\title{
Polipropileno/poliamida nahasteen konpatibilizazioa: azterketa morfologiko eta erreologikoa
} (Compatibilization of polypropylene polyamide blends: a morphological and rheological study)

\author{
Leire Sangroniz ${ }^{1}$, Jordana K. Palacios ${ }^{1}$, Mercedes Fernández ${ }^{1}$, \\ Alejandro J. Müller ${ }^{1,2}$, Antxon Santamaria ${ }^{1 *}$ \\ ${ }^{1}$ POLYMAT eta Polimeroen Zientzia eta Teknologia Saila, Kimikako Fakultatea \\ (UPV/EHU) \\ ${ }^{2}$ IKERBASQUE, Zientziarako Euskal Fundazioa \\ *antxon.santamaria@ehu.eus
}

DOI: $10.1387 /$ ekaia.17834

Laburpena: Polipropileno/Poliamida (PP/PA) nahasteak prestatu dira eta kopolimerokonpatibilizatzailea eta nanosilika gehitzeak nahaste horietan duen eragina aztertu da. Azterketa mikroskopikoak erakusten duenez, nahasteek emultsio antzeko morfologia dute, polipropilenoak fase jarraitua osatzen duelarik. Konpatibilizatzailea zein nanosilika gehitzeak PA tanten tamaina nabarmen murrizten duela antzematen da. Nahaste bitarrak fluxu jarraitu baten eraginpean daudenean, PA tanten koaleszentzia gerta daiteke eta, ondorioz, tanten tamaina handitu egiten da. Kopolimeroa zein nanosilika daukaten nahasteen kasuan, ordea, morfologia ez da eraldatzen fluxuaren eraginez. Fluxu oszilakorrak burutu dira nahaste desberdinen ezaugarri biskoelastikoak lortzeko. Neurketa biskoelastikoen bidez lortzen diren erlaxazio-espektroen azterketak morfologian gertatutako aldaketak detektatzeko gai direla frogatzen da.

Hitz gakoak: polimero-nahasteak, konpatibilizatzailea, nanosilika, morfologia, koaleszentzia, erlaxazio mekanikoak.

Abstract: Polypropylene/Polyamide (PP/PA) blends have been prepared and the effect of adding compatibilizer copolymer and nanosilica to the blends has been studied. Microscopic analysis shows that the blends exhibit an emulsion-like morphology, with polypropylene as a continuous phase. The addition of a compatibilizer, as well as nanosilica particles, reduces significantly the size of PA droplets. When the binary blend is submitted to a continuous flow, coalescence of PA droplets may occur, which leads to 
Leire Sangroniz, Jordana K. Palacios, Mercedes Fernández, Alejandro J. Müller, Antxon Santamaria

an increase of the droplets. However, for the blends containing copolymer or nanosilica, the flow does not induce changes in the morphology. Oscillatory flows have been carried out to obtain viscoelastic properties of the different blends. In this work, it is proved that the relaxation spectrum obtained from viscoelastic results are able to detect morphological changes.

Keywords: polymer blends, compatibilizer, nanosilica, morphology, coalescence, mechanical relaxation.

\section{SARRERA}

Gaur egun ohiko metal zein plastikoak ordezkatzeko, material hobeak eta ekonomikoagoak garatu behar dira. Polimeroen alorrean, helburu hori lortzeko bide desberdinak daude. Aukeretako bat polimero berriak sintetizatzea da monomero desberdinetatik abiatuta. Prozedura horren desabantailak kostu altua eta polimero horien garapenak denbora luzea behar duela dira. Baina badaude beste aukera batzuk, horien artean polimeroen nahaste fisikoa. Horren bitartez, material berriak modu ekonomikoan eta komertzializazio-denbora labur batez lor daitezke. Gainera, nahastearen konposizioa aplikazioen beharren arabera egokitu daiteke $[1,2]$.

Polimero-nahasteek garrantzi handia daukate polimeroen munduan, izan ere, 2010ean ekoiztutako polimeroen erdia polimero-nahasteak izan ziren. Nahasteen ezaugarriak aztertzea ezinbestekoa da material mota horien erabilera optimizatzeko [3].

Esan beharra dago polimeroak ez direla gehienetan termodinamikoki nahaskorrak izaten, orokorrean afinitate kimikorik ez baitago monomeroen artean. Ondorioz, bi polimeroz osaturiko nahasteak hainbat modutara antolatzen dira bi faseko morfologia desberdinak azalduz. Giro-tenperaturan polimero-nahasteak egoera solidoan egon behar diren arren, prozesaketa (estrusioa, injekzioa etab.) egoera fundituan egin behar da derrigorrean. Beraz, morfologiaren garapena egoera fundituan gertatzen da, bukaerako materiala prozesaketaren zehar fluxu baten mende dagoelarik. Behin nahastea hoztean, materiala solidotu egiten da fluxuan sortu den morfologia finkatuz. Morfologia eta fluxuaren arteko erlazioa ulertuta posible da aplikazioen araberako nahastearen morfologia egokitzea, prozesaketa-baldintza egokiak erabiliz.

Jakina da polimero-nahaste baten ezaugarriak nahastea osatzen duten polimeroen eta horien konposizioaren mendekoak direla, baina baita morfologiarenak ere. Bi faseko nahasteek morfologia desberdinak osa ditzakete ezaugarri desberdinak azalduz, 1. irudian ikus daitekeen bezala. Morfologiaren arabera propietateak aldatu egiten dira: tanta-matrize morfologia osatzen denean, sendotasun mekaniko ona azaltzen da; laminarra baldin bada, materialak hesi propietate onak izango ditu; morfologia ko-jarraitua 
osatzen bada, nahastearen propietateak bi homopolimeroenak baino hobeak izan daitezke; zuntzak osatzen badira, aldiz, erresistentzia ona izango du zuntzen luzeraren norabidean. Beraz, premiazkoa da polimero-nahasteen morfologia ondo ezaugarritzea eta morfologia hori egonkorra eta errepikakorra den ala ez jakitea $[1,2]$.

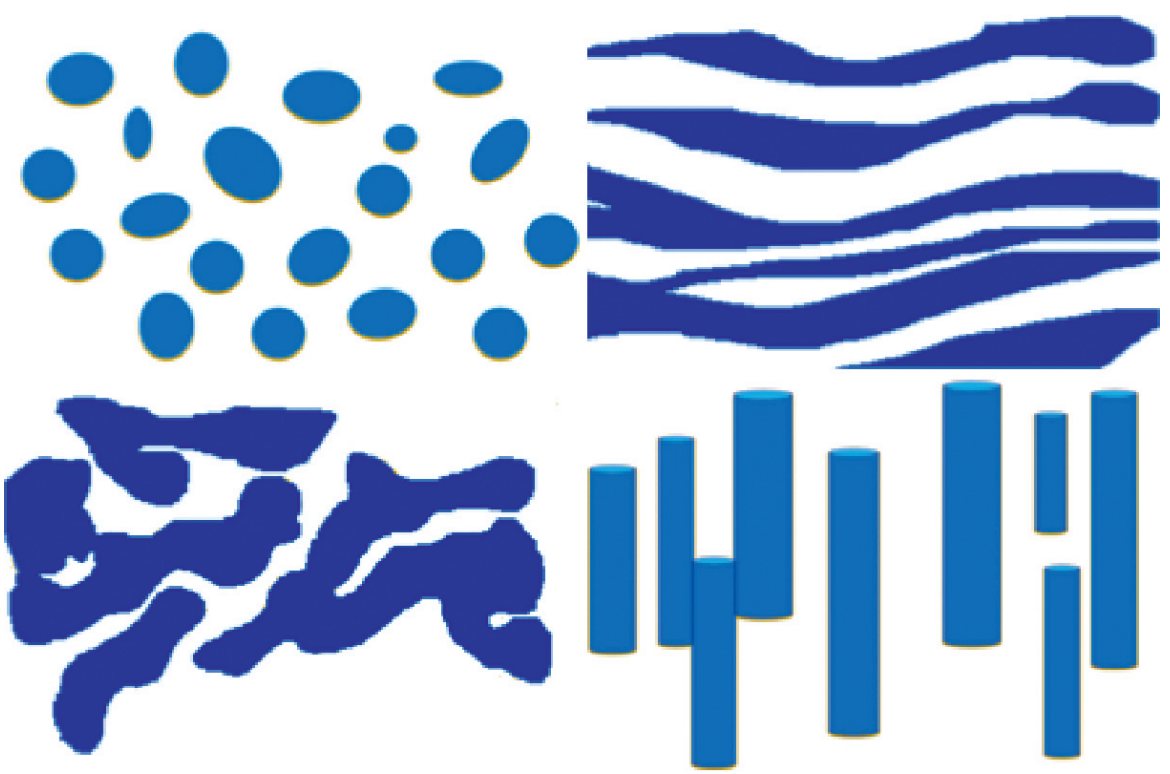

1. irudia. Bi fasez osaturiko polimero-nahasteek azal ditzaketen morfologiak: tanta-matrize morfologia, laminarra, ko-jarraitua eta zuntz-morfologia.

Morfologia egonkorreko nahasteak lortzeko modu egokiena konpatibilizazioa da. Kontuan izan behar da prozesaketan zehar tenperaturaren eta ebakiduraren ondorioz, morfologia aldatu egin daitekeela. Konpatibilizazioak morfologia egonkortzen du aipaturiko efektuetatik babestuz. Helburu horrekin, besteak beste, kopolimeroak edo kargak gehitu daitezke.

Kopolimero konpatibilizatzaile batek nolabaiteko zubi-lana, hau da, konpatibilizazioa, egin dezake polimero ezberdinen artean, tentsio interfaziala murrizten duelarik. Zenbat eta txikiagoa izan tentsio interfaziala, orduan eta tanta txikiagoak lortuko dira, nahastea egonkortuz. Horretaz gain, konpatibilizatzailea interfasean kokatzen denez tanten koaleszentzia ekiditen du prozesaketan zehar $[4,5]$.

Kargak, berriz, nahasteei zenbait propietate hobetzeko gehitzen zaizkie, hala nola ezaugarri mekanikoak, termikoak eta elektrikoak. Baina horretaz gain, nahastearen konpatibilizazioa eta, beraz, morfologia alda dezaketela 
Leire Sangroniz, Jordana K. Palacios, Mercedes Fernández, Alejandro J. Müller, Antxon Santamaria

ikusi da. Hala ere, ez dago oso argi zein den morfologian eragiten duen mekanismoa, aipatzen diren arrazoien artean, besteak beste, tentsio interfazialaren murrizketa edota hesi solido baten eraketa dira, azken horrek tanten koaleszentzia ekiditen duelarik.

Nahastearen baitan, kargen kokapena kargaren gainazalaren eta polimeroen arteko interakzioaren araberakoa da. Beraz, nahastea osatzen duten osagaien arteko tentsio interfaziala ezagututa eta horren bitartez bustitzeparametroa (wetting parameter) kalkulatuta kargen kokapena aldez aurretik zein izango den jakin daiteke. Bide horri jarraituz sistema desberdinentzat teorikoki kalkulatutako kargen kokapena esperimentalki lortutakoarekin bat etorri da. Hala ere, kontuan hartu behar da metodo horrek muga batzuk dituela, esaterako, kargen kokapena oreka termodinamikozko egoera batean zehaztu daiteke, baina polimeroak egoera fundituan daudelarik likatasuna oso altua izan ohi da; beraz, sistema ez da iristen oreka termodinamikora. Hori dela eta, efektu zinetikoak kontutan hartu behar dira: nahastea prestatzeko garaian materialak gehitzen direneko sekuentzia, polimeroen likatasuna eta partikulen migrazioa [6,7].

Lehen aipatu bezala, polimero-nahaste batek azaltzen dituen ezaugarriak morfologiaren mendekoak dira. Kontuan hartu behar da nahasteari fluxu bat aplikatuz gero, morfologia aldatu egin daitekeela, aldaketa maila globalean edo maila lokalean gerta daitekeelarik (2. irudia). Aldaketa glo-
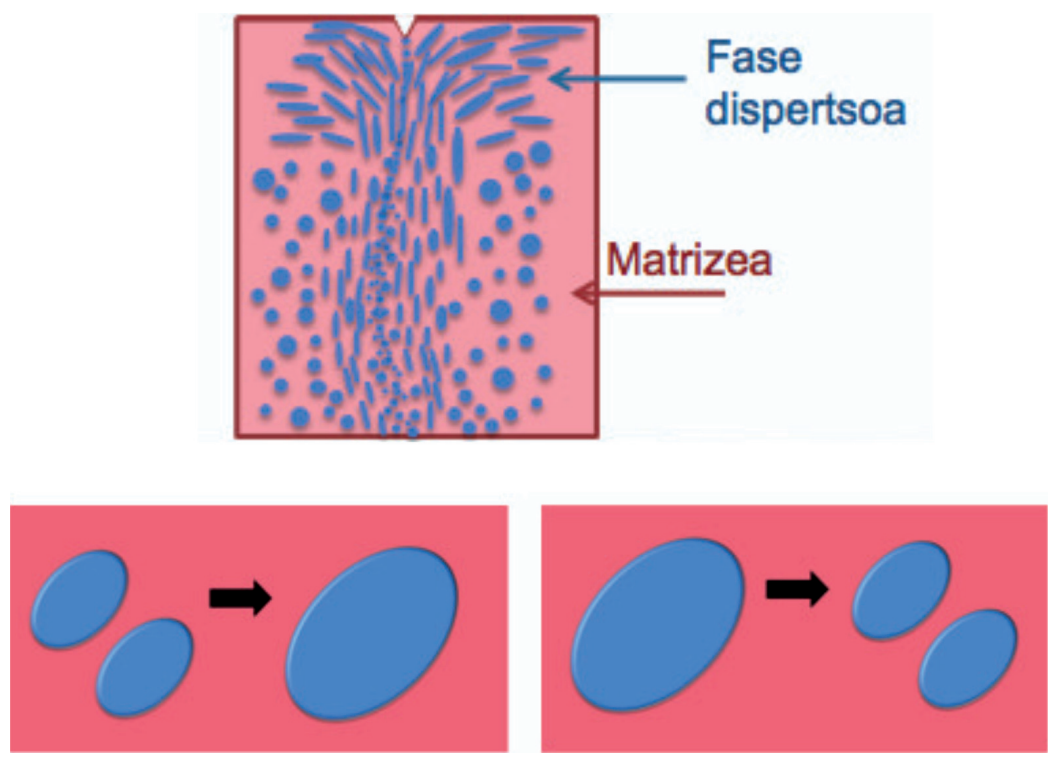

2. irudia. Fluxuaren eragina bi fasez osaturiko polimero-nahasteen morfologian, maila globalean (goiko irudia) eta maila lokalean (beheko irudiak): koaleszentzia (ezkerrean) eta tanten apurketa (eskuinean). 
balaren kasuan, fluxuak dispertsatutako fasearen migrazioa eragin dezake, horrela azal-nukleo egiturak edo soldadura-marrak agertzen direlarik. Aldaketa hori fluxu desberdinak ezartzean gertatzen da edota materialaren prozesaketan zehar. Beraz, sistemaren karakterizazioa premiazkoa da.

Morfologiaren aldaketa lokala gertatzen denean, tanten apurketa edo koaleszentzia gerta daiteke. Tanten apurketa esfortzu likatsuak eragiten duen deformazioaren ondorioz gertatzen da. Koaleszentzia, berriz, esfortzu interfazialaren ondorioz gertatzen da, horrek azalera interfaziala gutxitzeko joera baitu. Prozesu horretan 2 tanta edo gehiagok elkar jo eta tanta bakarra osatzen dute. Tanten apurketaren eta koaleszentziaren arteko lehia dago, beraz, amaieran lortuko den morfologia lehia horren araberakoa izango da [1].

Morfologia aztertzeaz gain, lan honetan ezaugarri erreologikoak aztertu dira. Jakina den bezala, erreologia materialen egitura aztertzeko teknika egokia da, horrela polipropilenoa/poliamida (PP/PA) nahasteari kopolimeroa zein nanosilika gehitzeak duen eragina aztertu da. Horretarako, anplitude txikiko neurketa oszilakorrak erabili dira (3. irudia). Neurketa horiekin lorturiko datuak erabilita espektro mekanikoak deritzenak eraiki dira, espektro horiek materialaren barne-egituraren inguruko informazioa ematen dutelarik. Espektro horiek lortzeko materialari esfortzu edo deformazio bat aplikatzen zaio modu periodikoan, eta energia disipatzen edo pilatzen duen aztertzen da. Energiaren pilaketa edo disipazioa denboraren, tenperaturaren edo deformazio abiaduraren mende azter daiteke espektro mekanikoa lortuz [8].
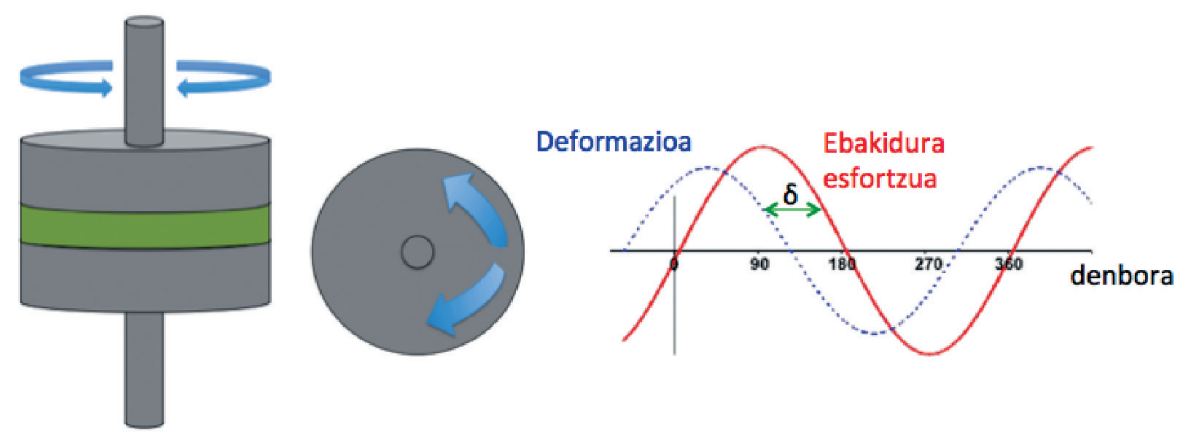

3. irudia. Anplitude txikiko neurketa oszilakorren eskema: ezkerrean erreometro baten geometria ageri da; eskuinean, deformazioa eta ebakidura-esfortzua denboran zehar.

Lan honetan erabili diren polimeroak PPa eta PA 6 izan dira; biak polimero termoplastiko oso ezagunak dira. Polipropilenoak propietate mekaniko, erresistentzia kimiko eta gogortasun handia azaltzen du; horretaz gain, erraz prozesa daiteke injekzioz edo estrusioz. Hala ere, beste zenbait propietate ez dira oso onak, esaterako talkarekiko erresistentzia. Polimero 
Leire Sangroniz, Jordana K. Palacios, Mercedes Fernández, Alejandro J. Müller, Antxon Santamaria

hori batez ere automobilgintzan, paketatzean edota zuntzak egiteko erabiltzen da. Poliamida, berriz, ingeniaritzako polimero termoplastikoa da eta amida taldeak ditu bere egituran. Propietate mekaniko onak azaltzen ditu: trakzio, flexio edo talkarekiko erresistentzia. Polimero horren aplikazio nagusiek automobilgintzan, industria elektronikoan, ehungintzan eta paketatzean dute eragina. Polipropilenoari poliamida gehitu zaio zenbait ezaugarri hobetzen dituelako, adibidez propietate mekanikoak, gasekiko iragazkortasuna eta egonkortasun termikoa [9-11].

Artikulu honetan polipropileno/poliamida nahasteari kopolimeroa zein nanosilika gehitzeak nahastearen morfologian daukan eragina aztertu da teknika mikroskopikoak erabiliz. Fluxuak morfologian daukan eragina ere aztertu da; horretarako, fluxu jarraitua aplikatuz. Azkenik, nahaste desberdinen neurketa erreologikoak gauzatu dira eta erlaxazio espektroak lortu dira morfologian gertatzen diren aldaketak antzemateko.

\section{LAN ESPERIMENTALA}

Erabili diren polimeroak Repsol etxeko polipropilenoa eta Lanxess etxeko poliamida 6 izan dira. Konpatibilizatzaile bezala, anhidrido maleikoa txertatuta duen polipropilenoa (PPgMA) erabili da, Du Pont etxekoa. Nanosilika hidrofobikoa, berriz, CABOT etxekoa da agregatuen tamaina 200-300 nm-koa delarik.

Nahastea prestatzeko, torloju bikoitzeko Collins estrusorea erabili da $200-240^{\circ} \mathrm{C}$-ko tenperatura artean eta 40 bira minutuko abiaduran. Aztertu beharreko laginak konpresio bidezko moldaketaz lortu dira. Nahasteen konposizioari dagokionez, PP/PA nahastea 80/20 proportzioan dago, konpatibilizatzailea pisu totalarekiko $\% 2$ an gehitu da eta nanosilika pisu totalarekiko \% 5ean.

Nahasteen morfologia aztertzeko, ezaguna den SEM mikroskopia elektronikoa erabili da. Fluxuak morfologian daukan eragina aztertzeko, fluxu jarraitua aplikatu da ARG2 erreometroa erabiliz.

\subsection{Neurketa oszilakorrak}

Erreologiari dagokionez, neurketa oszilakorrak burutu dira materiala urtua dagoelarik ARG2 erreometroan. Horretarako lagina bi xaflen artean kokatzen da, ikus 3. irudia; goiko xafla alde batera zein bestera mugi daiteke. Kasu honetan, neurketa oszilakorrak egin direnez, esfortzua edo deformazioa modu periodikoan, hau da, sinusoidalki, aplikatzen da grafikoan ikus daitekeen bezala. Bi funtzioen artean delta desfase bat sortuko da; desfase hori biskoelastikotasunaren araberakoa da. Neurketa horiek anplitude txikitan egiten badira, sistemaren egitura ez da aldatzen. Anplitude handiak 
aplikatuz, ordea, egitura eta, ondorioz, erantzun biskoelastikoa aldatzen da. Lan honetan frekuentzia-ekorketak egin dira $100 \mathrm{~Hz}$-etik 0,005 Hz-era $220^{\circ} \mathrm{C}$-an eta anplitude txikiak erabiliz.

\section{EMAITZAK}

\subsection{Morfologia}

4. irudian nahaste desberdinen SEM argazkiak azaltzen dira; ikus daitekeen bezala, nahasteek tanta-matrize edo emultsio-itxurako morfologia daukate. PA polimeroak dispertsatutako fasea edo tantak osatzen ditu, hori baita konposizio txikienean dagoena. Konpatibilizatzailea gehitzean, tanten tamaina 4 aldiz murrizten da 4 . irudian eta 1 . taulan ikus daitekeen moduan. Sarreran aipatu bezala, konpatibilizatzaileek tentsio interfaziala murrizten dute kantitate txikienean dagoen fasearen dispertsioa erraztuz [12-14]. Nanosilika hidrofobikoaren gehikuntzak tanten tamainaren murrizketa areagotzen du, konpatibilizatzailea duen nahastearekin alderatuta tamaina erdira jaisten delarik. Morfologia-aldaketa hori kargen kokapenari zor zaio, izan ere, nanosilika hori interfasean kokatzen da; horrela, PA tantak inguratzen ditu hesi fisiko bat eratuz. Modu horretan tanten koaleszentzia ekiditen da eta, ondorioz, tanten tamaina txikiagoa da $[6,7,11,15]$.
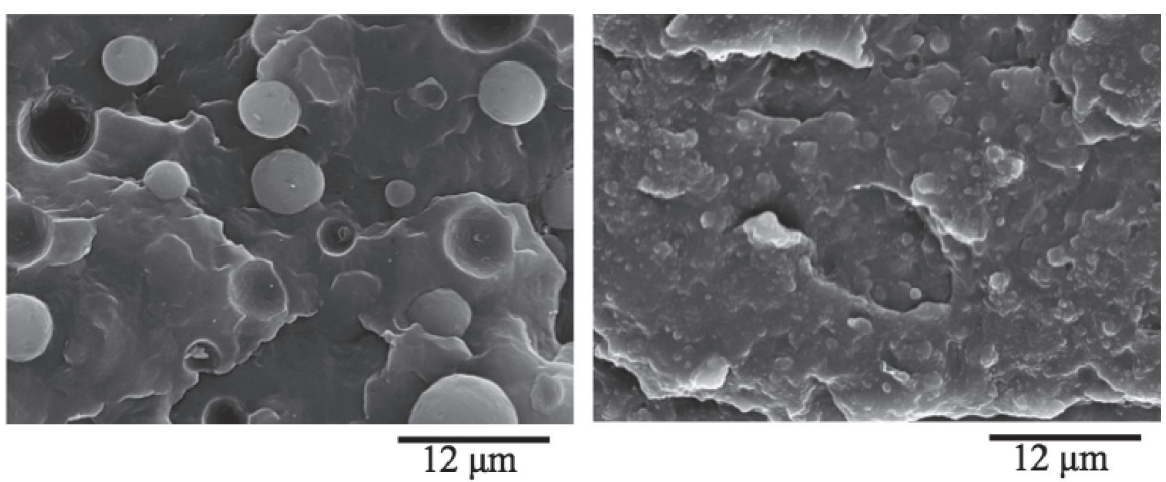

4. irudia. PP/PA eta PP/PA/PPgMA nahasteen morfologia SEM bidez antzemanda [15].

1. taula. Nahaste desberdinen PA tanten tamaina, $d_{n}(\mu \mathrm{m})$.

\begin{tabular}{lc}
\hline \multicolumn{1}{c}{ Nahastea } & $d_{n}(\mu \mathrm{m})$ \\
\hline PP/PA & 1,6 \\
PP/PPgMA/PA & 0,4 \\
PP/PPgMA/PA/NSH & 0,2 \\
\hline
\end{tabular}


Leire Sangroniz, Jordana K. Palacios, Mercedes Fernández, Alejandro J. Müller, Antxon Santamaria

Sarreran aipatu bezela, prozesaketan materialak fluxu desberdinak jasan ditzake morfologia eraldatuz; ondorioz, sistemaren ezaugarritzea oinarrizkoa da. Hori dela eta, kasu honetan ebakidurazko fluxuak sistema horietan daukan eragina aztertu da, horretarako, 0,4 1/s-ko fluxu jarraitua aplikatuz. 5. irudian ikus daitekeen bezala, PP/PA nahasteari fluxua aplikatzean, denbora apaletan likatasunean maximo bat azaltzen da; maximo hori tanten deformazioari dagokio. Ondoren, likatasuna txikiagotu egiten da denboran zehar, horrek PA tanten koaleszentzia gertatzen ari dela adierazten digu $[15,16]$.

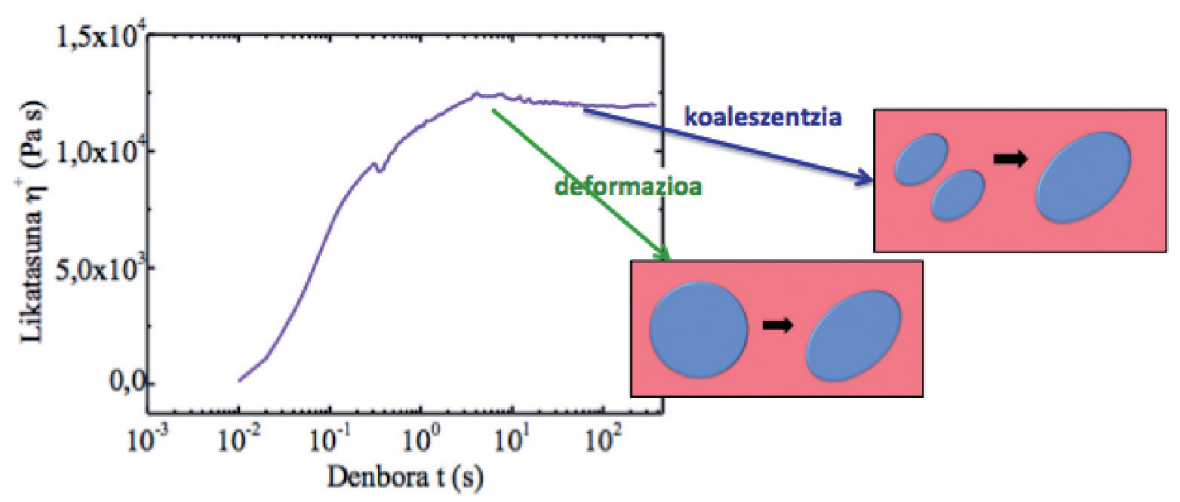

5. irudia. Likatasun iragankorra denboraren aurrean PP/PA nahastearentzat, 0,4 1/s-ko ebakidura-abiadura aplikatzen denean $220^{\circ} \mathrm{C}$-an [15].

Fluxua jasan duten laginen azterketa mikroskopikoek PA tanten tamaina nabarmen areagotzen dela egiaztatzen dute (6. irudia). Kopolimeroa edo nanosilika daukaten nahasteen kasuan, ordea, ez dago koaleszentziarik

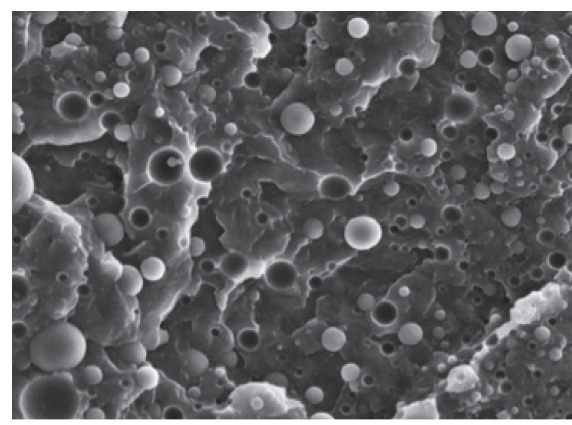

$50 \mu \mathrm{m}$

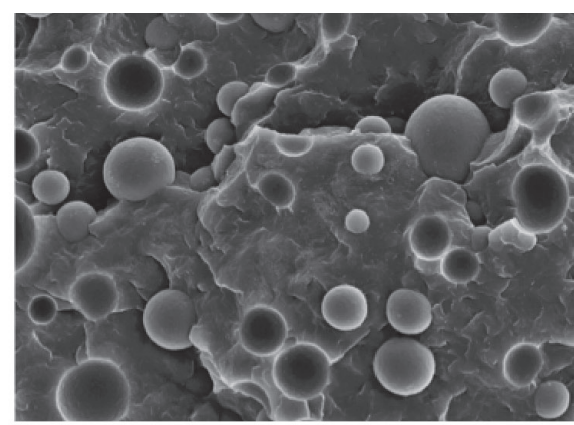

$50 \mu \mathrm{m}$

6. irudia. PP/PA nahasteen morfologia fluxua jasan aurretik (egoera geldoan, ezkerrean) eta fluxua jasan ondoren (eskuinean) [15]. 
nahiz eta fluxua aplikatu den. Kopolimeroaren kasuan, tanten koaleszentzia ekiditea bi tanta elkarrengana gerturatzean, interfasean dagoen konpatibilizatzailearen ondorioz sortzen den eragozpen esterikoari zor zaio [17]. Nanosilikaren kasuan, berriz, partikulek PA tantak inguratzen dituzte hesi solido bat eratuz (ikus 7. irudia) eta horren ondorioz, koaleszentzia ekiditen da. Beraz, kopolimeroa zein kargak gehitzea morfologia egonkortzeko modu aproposak direla frogatzen da $[7,15,16]$.
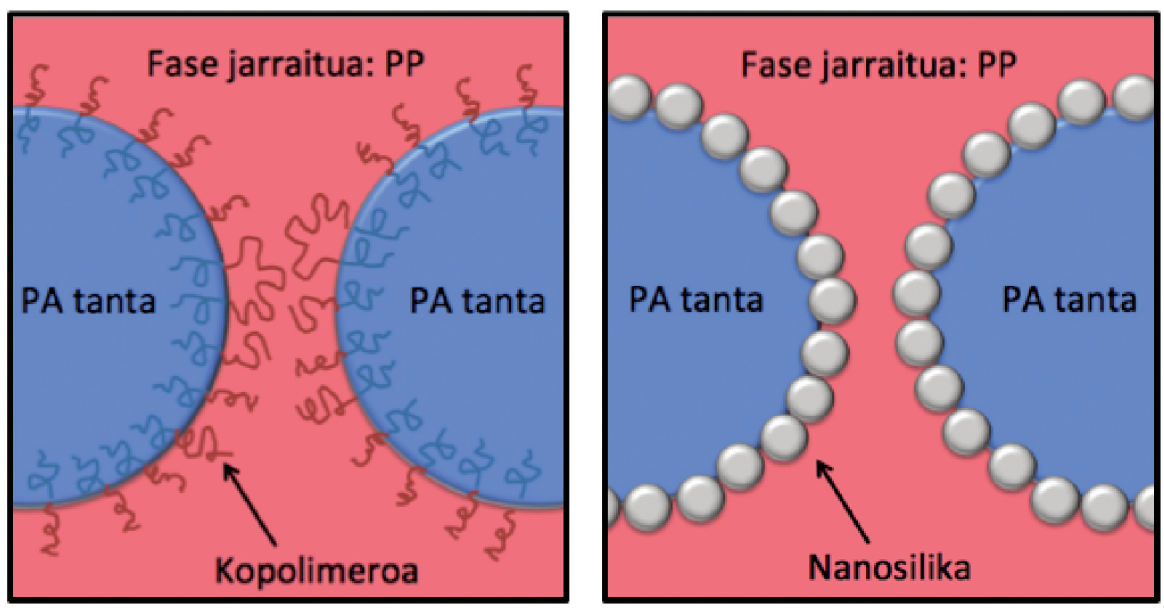

7. irudia. Kopolimero konpatibilizatzailearen eta nanosilikaren eragina nahastearen morfologian. Polipropilenoak (PP) fase jarraitua osatzen du, poliamidak (PA), tantak.

\subsection{Erreologia}

Anplitude txikiko neurketa oszilakorrak egin dira PP/PA nahaste desberdinekin materialaren ezaugarri elastiko eta likatsuak lortzeko, materialaren egitura suntsitu gabe. 8. irudian, pilatze-modulua edo modulu elastikoa deritzona irudikatu da frekuentziaren aurrean, parametro horrek pilatutako energia adierazten duelarik. Frekuentzia apaletan, denbora esperimental luzeen baliokidea dena, polimero-kate osoaren mugimenduak nabaritzen dira; frekuentzia garaietan, berriz, denbora esperimental laburrak izanik, kateen mugimendu lokalak soilik antzematen dira. PP eta PA homopolimeroek daukaten portaera aztertzen bada ikus daiteke PP/PA nahasteak homopolimeroekin alderatuta, moduluaren balio altuagoak azaltzen dituela; hau interfaseari zor zaio, izan ere, horrek kontribuzio elastiko bat duelako. Kopolimeroa gehituz, modulu elastikoa handitzen da; hori tanten tamaina txikitu eta ondorioz, interfasea areagotzen delako gertatzen da. Nanosilika gehitzean, berriz, portaera nabarmen aldatzen da: frekuentzia apaletan, modulu elastikoak lautada bat azaltzen du partikula eta polimero-kateen arteko 
Leire Sangroniz, Jordana K. Palacios, Mercedes Fernández, Alejandro J. Müller, Antxon Santamaria

interakzioak direla eta, sare elastiko bat osatzen delarik. Sare horrek fluxua eragozten du, izan ere, frekuentzia apaletan $\mathrm{G}^{\prime}>\mathrm{G}^{\prime \prime}$ betetzen da [18].
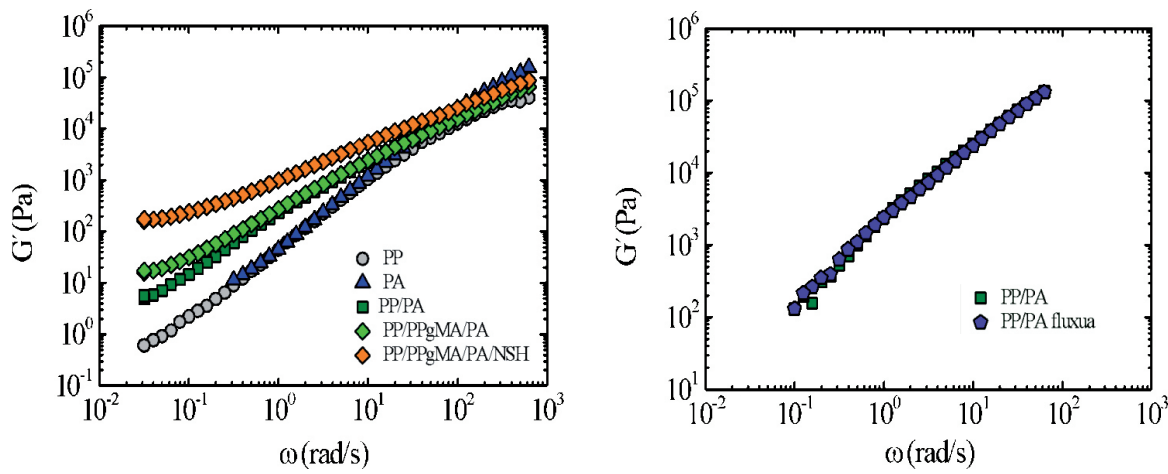

8. irudia. Anplitude txikiko neurketa oszilakorren bidez lorturiko modulu elastikoaren emaitzak $220{ }^{\circ} \mathrm{C}$-an: a) nahaste desberdinentzat eta b) PP/PA nahastearentzat koaleszentzia jasan aurretik eta koaleszentzia ondoren.

6. irudian koaleszentzia jasan duen PP/PA nahastea hasierako laginarekin alderatzen da, helburua parametro erreologikoak morfologian gertatzen diren aldaketak detektatzeko gai ote diren aztertzea da. 8. irudian ikus daitekeen bezala, frekuentzia altuetan bi laginen datuak gainezarri egiten dira degradaziorik ez dela egon adieraziz. Koaleszentzia jasan duten laginen kasuan, frekuentzia ertainetan modulu elastikoa zertxobait jaisten dela ikus daiteke. Tanten koaleszentzia gertatzean, azalera interfaziala txikiagoa da tantak urriagoak direlako, eta ondorioz, kontribuzio elastikoa murrizten da. Hala ere, azpimarratzekoa da hasierako laginaren eta koaleszentzia jasan duenaren portaerak oso antzekoak direla; beraz, anplitude txikiko neurketa oszilakorrak ez dira gai morfologian gertatzen diren aldaketak antzemateko.

Morfologian gertatu diren aldaketak nabaritzeko, espektro mekanikoen azterketara jo beharra dago. Neurketa erreologikoen bidez, espektro mekaniko mota bat lor daiteke, erlaxazio-espektroa deritzona. Espektro horiek Maxwellen eredu orokorra erabiliz eraiki daitezke (ikus 1 eta 2 ekuazioak); ekuazio horiek material biskoelastikoen mugikortasun molekularraren gaineko informazioa ematen digute.

$$
\begin{aligned}
& G^{\prime}(\omega)=\int_{-\infty}^{+\infty} H(\lambda) \frac{\omega^{2} \lambda^{2}}{1+\omega^{2} \lambda^{2}} d \ln \lambda \\
& G^{\prime \prime}(\omega)=\int_{-\infty}^{+\infty} H(\lambda) \frac{\omega \lambda}{1+\omega^{2} \lambda^{2}} d \ln \lambda
\end{aligned}
$$


Espektroan, erlaxazio-mekanismoen populazioa erlaxazio-denboraren aurrean irudikatzen da $(\lambda \times \mathrm{H}$ vs $\lambda)$. Maximo batek erlaxazio-prozesu baten kontzentrazioa adierazten du denbora jakin baterako. Aipatu behar da espektroa materialaren egiturarekin erlazionatuta dagoela, izan ere, zenbat eta luzeagoa den polimero-katea, orduan eta handiagoa da berari dagokion erlaxazio-denbora. Horrela, material polimeriko batean kate batzuek pisu molekular altua baldin badute, espektroa zabaldu egiten da denbora handiagoetara.

Nahaste gehienetan bi maximo agertzen dira, polimero bakoitzaren erlaxazio-denborak desberdinak baitira. Zenbait kasutan hirugarren maximo bat azaldu daiteke erlaxazio-denbora handiagoetan, dispertsatutako fasearen formaren erlaxazio-denbora dena. Denbora hori deformatutako tantek hasierako egoerara itzultzen direneko prozesuarekin erlazionatuta dago, hau da, tentsio interfazialarekin lotuta dago $[8,19,20]$.
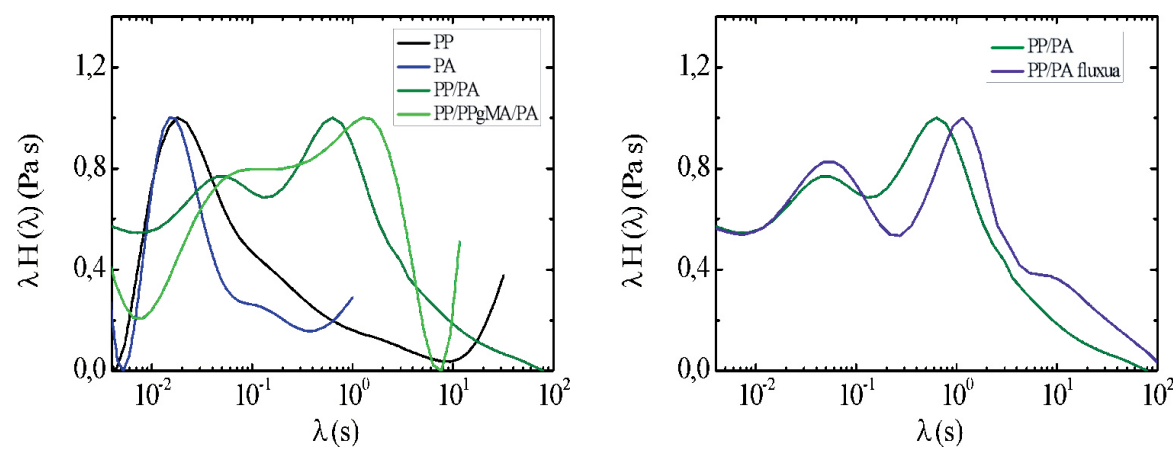

9. irudia. Erlaxazio-espektro mekanikoak $220^{\circ} \mathrm{C}$-an: a) polimero huts eta nahaste desberdinentzat eta b) PP/PA nahastearentzat kolaeszentzia jasan aurretik eta jasan ondoren. Koaleszentziaren ondorioz, espektroa denbora handiagoetara desplazatzen da.

9. irudian erlaxazio-espektroa azaltzen da. Ikus daitekeen bezala, PP eta PA homopolimeroek maximo berdina azaltzen dute, denbora apaletan, nahiz eta polipropilenoaren espektroa zabalagoa izan. PP/PA nahasteari dagokionez, bi maximo antzeman daitezke, lehenengoa 0,025 s-tan PP eta PA fase puruei dagokiona eta bigarren maximoa, berriz, $0,9 \mathrm{~s}$-tan ageri dena, tanten formaren erlaxazioari zor zaiona. Kopolimeroa gehitzean, bi maximoak denbora handiagoetara lerratzen dira, 0,07 eta 1,25 s-tan azaltzen direlarik. Gertakari hori aztertzeko, 2 efektu hartu behar dira kontuan: alde batetik, tanten tamaina txikiagotu dela, eta bestetik, tentsio interfaziala murriztu dela. Erlaxazio-denbora handitzeak gailentzen den efektua tentsio interfazialaren murrizketari zor zaiola adierazten du [14].

PP/PA nahaste bitar hutsen kasua kontsideratuta fluxua aplikatzearen eragina azter daiteke. 9. irudian ikus dezakegunez, fluxua jasan duen la- 
Leire Sangroniz, Jordana K. Palacios, Mercedes Fernández, Alejandro J. Müller, Antxon Santamaria

ginaren kasuan, bigarren maximoa (interfaseari dagokiona) erlaxazio-denbora luzeagoetara lerratzen da. Lerratze hori tanten tamaina handiagoa izateari zor zaio (6. irudia), izan ere, koaleszentzia gertatu denez, erlaxaziodenbora tanten tamainarekiko zuzenki proportzionala baita. Emaitza horiek frogatzen dute erlaxazio-espektroak gai direla PP/PA sisteman gertatu den morfologia-aldaketa modu argian detektatzeko.

\section{ONDORIOAK}

PP/PA nahasteen morfologia eta ezaugarri erreologikoak aztertu dira. Mikroskopia bidez eginiko azterketa morfologikoak erakusten du kopolimero konpatibilizatzailea zein nanosilika gehitzeak tanten tamaina nabarmen murrizten duela. Kopolimeroaren kasuan, tanten tamainen txikiagotzea tentsio interfaziala murrizten delako gertatzen da, nanosilikaren kasuan, berriz, tanten koaleszentzia ekiditen duen hesi fisiko bat eratzen delako. Horretaz gain, fluxuak morfologian duen eragina ere aztertu da: PP/PA nahaste bitarren kasuan, koaleszentzia gertatzen da, tanten tamaina areagotuz. Kopolimero konpatibilizatzailea eta nanosilika daukaten nahasteen kasuan, ordea, ez da koaleszentziarik gertatzen. Beraz, gehigarri horiek morfologia modu eraginkorrean egonkortzen dute nahastea.

Erreologiari dagokionez, nanosilikaren gehikuntzak portaera biskoelastikoa nabarmen aldatzen du. Izan ere, partikulen eta polimero-kateen arteko interakzioen bidez, sare bat osatzen da eta horrek fluxua ezabatzen du. Hala ere, erreologiaren bidez lorturiko oinarrizko parametroak ez dira gai PP/PA nahaste bitarrean fluxuaren ondorioz gertatutako koaleszentzia detektatzeko. Erlaxazio-espektro mekanikoen bitartez, ordea, posible da koaleszentzia detektatzea, koaleszentzia jasan duen laginaren kasuan erlaxazio-denbora handiagoak lortzen baitira. Beraz, ondoriozta daiteke erlaxazio-espektroak asko aldatzen direla morfologian gertatzen diren aldakuntzekin, horrek nahasteen karakterizazioari begira bide berriak zabaltzen dituelarik.

\section{ESKER ONAK}

Lan hau UPV/EHUk (UFI 11/56) eta Eusko Jaurlaritzak (GIC IT-58613) finantzatuta burutu da. L.S.ek Espainiako gobernuari eskertzen dio doktore-tesia egiteko FPU diru-laguntza emateagatik. 


\section{BIBLIOGRAFIA}

[1] UTRACKI L.A. 2014. Polymer Blends Handbook. Springer, Netherlands.

[2] PAUL D.R., NEWMAN S. 1978. Polymer Blends Volume 1. Academic Press, New York.

[3] THOMAS, S., GROHENS, Y. eta JYOTISHKUMAR, P. 2015. Characterization of Polymer Blends; Miscibility, Morphology, and Interface. WileyVCH Verlag GmbH \& Co.

[4] KONING, C., VAN DUIN, M., PAGNOUlle eta C. JEROME, R. 1998. «Strategies for Compatibilization of Polymer Blends». Progress in Polymer Science 23, 707-757.

[5] BOUDENNE, A., IBOS, L., CANDAU, Y. eta SABU, T. 2011. Handbook of Multiphase Polymer Systems. John Wiley and Sons, UK.

[6] THOMAS, S., SHANKS, R. eta CHANDRASEKHARAKURUP, S. 2014. Nanostructured Polymer Blends. Elsevier, Amsterdam.

[7] TAGUET, A., CASSAGNAU, P. eta LOPEZ-CUESTA, J.M. 2014. «Structuration, selective dispersion and compatibilizing effect of (nano)fillers in polymer blends». Progress in Polymer Science 39, 1526-1563.

[8] FERRY, J.D. 1980. Viscoelastic Properties of Polymers. John Wiley and Sons, New York.

[9] TRIPATHI, D. 2002. Practical Guide to Polypropylene. Rapra Technology LT.D., UK.

[10] PAGE, I.B. 2000. Polyamides as Engineering Thermoplastic Materials. Rapra Publishing, UK.

[11] SANGRONIZ, L., MONCERRATE, M.A., DE AMICIS, V.A., PALACIOS, J.K., FERNÁNDEZ, M., SANTAMARIA, A., SÁNCHEZ, J.J., LAOUTID, F., DUBOIS, P. eta MÜLLER, A.J. 2015. «The outstanding ability of nanosilica to stabilize dispersions of nylon 6 droplets in a polypropylene matrix». Journal of Polymer Science: Part B 53, 1567-1579.

[12] GERMAIN, Y., ERNST, B., GENELOT, O. eta DHAMANI, L. 1994. «Rheological and morpohlogical analysis of compatibilized polypropylene/polyamide blends ». Journal of Rheology 38, 681- 697.

[13] SHI, D., KE, Z., YANG, J., GAO, Y., WU, J. eta YIN, J. 2002. «Rheology and morphology of reactivelycompatibilized PP/PA6 blends». Macromolecules 35, 8005-8012.

[14] SHI, D., HU, G.H., KE, Z., LI, R.K.Y. eta YIN, J 2006. «Relaxation behavior of polymer blends with complex morphologies: Palierne emulsion model for uncompatibilized and compatibilized PP/PA6 blends». Polymer 47, 4659-4666.

[15] SANGRONIZ, L., PALACIOS, J.K., FERNÁNDEZ, M., EGUIAZABAL, J.I., SANTAMARIA, A. eta MÜLLER, A.J. 2016. «Linear and non-linear rhelogical behavior of polypropylene/polyamide blends modified with a compatibilizer agent and nanosilica and its relationship with the morphology». European Polymer Journal 83, 10-21. 
Leire Sangroniz, Jordana K. Palacios, Mercedes Fernández, Alejandro J. Müller, Antxon Santamaria

[16] NOFAR, M., MAANI, A., SOJOUDI, H., HEUZEY, M.C. eta CARREAU, P.J. 2015. «Interfacial and rheological properties of PLA/PBAT and PLA/ PBSA blends and their morphological stability under shear flow». Journal of Rheology 59, 317-333.

[17] VAN HEMELRIJCK, E., VAN PUYVELDE, P., VEMANKAR, S., MACOSKO, C.W. eta MOLDENAERS, P. 2004. «Interfacial elasticity and coalescence suppression in compatibilized polymer blends». Journal of Rheology 48, 143-158.

[18] FERNANDEZ, I., SANTAMARIA, A., MUÑOZ, M.E. eta CASTELL, P. 2007. «A rheological analysis of interactions in phenoxy/organoclay nanocomposites». European Polymer Journal 43, 3171-3176.

[19] VINCKIER, I., MOLDENAERS, P. eta MEWIS, P. 1996. «Relationship between rheology and morphology of model blends in steady shear flow». Journal of Rheology 40, 613-631.

[20] SOUZA, A.M.C. eta DEMARQUETTE, N.R. 2002. «Influence of coalescence and interfacial tension on the morphology of PP/HDPE compatibilized blends». Polymer 43, 3959-3967. 